\title{
Relationship between Organizational Justice and Job Satisfaction as Perceived by Jordanian Physical Education Teachers
}

\author{
Ziad Lutfi Altahayneh $^{1}$, Aman Khasawneh ${ }^{1} \&$ Abedalbasit Abedalhafiz ${ }^{1}$ \\ ${ }^{1}$ Faculty of Physical Education and Sport Sciences, Hashemite University, Jordan \\ Correspondence: Ziad Lutfi Altahayneh, Faculty of Physical Education and Sport Sciences, Hashemite \\ University, Zarqa, Jordan. Tel: 96-2-77721-1517. E-mail: saifziad@yahoo.com
}

Received: November 2, 2013

Accepted: December 19, 2013 Online Published: January 26, 2014

doi:10.5539/ass.v10n4p131

URL: http://dx.doi.org/10.5539/ass.v10n4p131

\begin{abstract}
This study aimed at exploring the relationship between organizational justice and job satisfaction as perceived by Jordanian physical education teachers. Participants consisted of 166 physical education teachers selected from public schools in Jordan. Organizational Justice Scale and Job in General Scale were used to collect the data. The findings revealed that the majority of physical education teachers were satisfied with their job in general and their perceptions about organizational justice were positive. Furthermore, the findings showed a positive and significant relationship between all dimensions of organizational justice and teachers' job satisfaction. Interactional justice was the best predictor of teachers' job satisfaction followed by procedural justice and distributive justice respectively. The full prediction model explained $19 \%$ of the variance in job satisfaction of physical education teachers in Jordan.
\end{abstract}

Keywords: organizational justice, satisfaction, schools, teachers, physical education, Jordan

\section{Introduction}

Job satisfaction or employee satisfaction is one of the most comprehensively measured and researched topics in the fields of management and organizational psychology. However, a universal definition of job satisfaction has yet to be established. Chelladurai (1999) identified job satisfaction as a person's evaluation of behavioral, cognitive, and emotional elements in his/her job responsibilities.

Job satisfaction is a positive emotional condition resulting from the pleasure a worker derives from the job (Dawis \& Lofquist, 1984; Spector, 1997). Job satisfaction is basically how people feel about their work and different aspects of their work (Spector, 1997). It is the workers' negative or positive attitudes towards his/her job (Greenberg \& Baron, 2008). This is echoed by Moorhead and Griffin (2004) who said that "job satisfaction is the extent to which a person is gratified or fulfilled by his or her work" (p. 99).

Interest in job satisfaction proceeds from its association with other significant organizational outcomes (Zainalipour, Fini, \& Mirkamali, 2010). One of the most important concepts related to job satisfaction is organizational justice. In 1987, Greenberg first used the term "organizational justice" to refer to the ethical and fair treatment of employees in the workplace.

Organizational justice is usually conceptualized with three components: distributive, procedural, and interactional justice (Cropanzano, Byrne, Bobocel, \& Rupp, 2001; Masterson, Lewis, Goldman, \& Taylor, 2000). However, Organizational justice models that have been proposed and explored have ranged from one to four components (Colquitt, Conlon, Wesson, Porter, \& Ng, 2001).

The first justice component is distributive which was defined by Greenberg (1990) as an individual's judgment or perceived fairness of resource allocation, based upon the produced outcomes of the individual compared to the expected inputs. The foundation of this definition is based in Adams' (1965) theory of equity. Adams proposed that individuals arrive at a sense of organizational equity or inequity through the comparison of ratio inputs (contributions) and outputs (rewards) to other workers within an organization. In cases of organizations creating a perception of equity within the workplace, employees will be satisfied and contented. Equity theory suggests individuals who perceive their ratio of inputs to be lower than the outputs received will feel guilty. In contrast, workers who perceive their ratios of inputs to be higher than the outputs received will feel angry (Thorn, 2010).

Procedural justice, the second component, is identified as individual's perception of fairness based upon 
organization policies and the processes by which these policies are put into action (Greenberg \& Colquitt, 2005). Procedural justice is concerned with the procedures for determining the outcomes to various individuals and units (Chelladurai, 1999). Procedural justice perceptions arose from work conducted by Thibaut and Walker (1975) as part of their procedural justice theory and presumed to be indispensable to employees' research and practice (Cropanzano, 2001).

In 1986, Bies and Moag introduced a third justice component within the organizational justice literature called interactional justice. Interactional justice is defined as the perceived fairness of individuals with organizational interpersonal communications (Greenberg \& Colquitt, 2005). Bies developed the theory of interactional justice through his own personal interactions with individuals. He noticed that individual's assessment of interpersonal treatment was process focused, while the actual interaction was not a formal procedure. Bies and Moag (1986) explained that interactional treatment is conceptually different from the structuring of procedures, and can therefore be separated as unique dimension of organizational justice (Thorn, 2010).

The relationship between justice perceptions and job satisfaction is well established in Western literature (e.g., Bakhshi, Kumar, \& Rani, 2009; Bhupatkar, 2003; Fatt, Khin, \& Heng, 2010; Malik \& Naeem, 2011; Nojani, Arjmandnia, Afrooz, \& Rajabi, 2012; Schappe, 1998; Schmiesing, Safrit, \& Gliem, 2003). For example, Schappe (1998), Colquitt et al. (2001), and Bakhshi et al. (2009) reported that distributive justice was an important predictor of job satisfaction. Furthermore, Masterson et al. (2000) found procedural justice to be a stronger predictor of job satisfaction than interactional justice.

The findings of Zainalipour et al. (2010) study showed significant positive relationships between job satisfaction and organizational justice. Distributive justice and interactional justice positively correlated with four facets of job satisfaction namely, supervision, coworker, pay and promotion and they did not have correlation with nature of job as a facet of job satisfaction.

In a non-western context, Al-Zu'bi (2010) investigated the relationship between organizational justice and job satisfaction in Jordan industrial companies. He found a significant positive correlation between employees' satisfaction and all dimensions of organizational justice (i.e., distributive, procedural and interactional justice). Elamin and Alomaim (2011) studied the effects of organizational justice perceptions on job satisfaction, and self-perceived performance in Saudi Arabia. They found that perceptions of organizational justice affect job satisfaction for both Saudi and non-Saudi employees.

Despite the fact that research on organizational justice perceptions and their influence on job satisfaction and different work outcomes has received great attention from the academic scholars and practitioners in the West, a very few studies has studied the association between organizational justice job satisfaction in different cultures, specifically the Middle East and Arab countries. If the target is to develop a general theory in organizational justice, research must surpass the U.S. and European context (Leung \& Stephan, 2001). Therefore, the current study aims to examine the perceptions of organizational justice and the job satisfaction of physical education teachers in Jordan. In addition, it is aiming at examining the relationship between teachers' perceptions of organizational justice and teachers' job satisfaction.

\section{Research Questions}

Three primary research questions guide this study.

1) What are the perceptions of physical education teachers about organizational justice in their schools?

2) What is the level of job satisfaction of Jordanian physical education teachers?

3) Is there a relationship between organizational justice and overall job satisfaction of Jordanian physical education teachers?

\section{Method}

\subsection{Participants}

Two hundred questionnaires were administered to a randomly selected sample of physical education teachers working in public schools in the education directorate of Zarqa during the academic year 2011-2012. Of these, 166 were completed and returned, yielding a response rate of $83 \%$. Out of the 166 participants, 88 were females (53\%) and 78 were males (47\%). The participants' age ranged from 22 years to 58 years, with a mean of 38.10 years and a standard deviation of 8.40 years. In addition, participants' years of experience ranged from 1 to 35 years $(M=11.54$ years, $S D=6.86)$. 


\subsection{Instruments}

\subsubsection{Organizational Justice Scale (OJS)}

The OJS developed by Niehoff and Moorman (1993) is a 20-item self-reported questionnaire. It measures three components of organizational justice: (a) distributive justice (5 items) assess participants' perceptions regarding the fairness of different work outcomes, (b) procedural justice ( 6 items) assess participants' perceptions regarding the formal decision-making process and fairness of procedures in the organization, and (c) interactional justice ( 9 items) assess participants' perceptions regarding the fairness of treatment they receive from their managers. Participants were asked to respond on a 5-point Likert scale ranging from 1 (strongly disagree) to 5 (strongly agree).

The OJS was also utilized in the educational context to measure organizational justice perceptions (e.g., Dundar \& Tabancali, 2012; Gurbuz \& Mert, 2009; Zainalipour et al., 2010). Gurbuz and Mert, (2009) used the OJS to test the perception of fairness of Turkish teachers. Reliability estimates for distributive, procedural, and interactional justice were $.748, .851$, and .941 respectively.

\subsubsection{Job in General (JIG) Scale}

The JIG was developed by Ironson, Smith, Brannick, Bison, and Paul (1989) to evaluate people's overall job satisfaction. The JIG consists of 18 items and each item is an adjective or short phrase regarding the job in general. The JIG uses three responses for each item: (yes) if the respondents agree, (no) if they disagree, and (?) if they aren't sure about the item describing their job. Scoring for the JIG is done by giving each "yes" response a score of 3, "no" response a score of 0 and "?" a score of 1 . Scores are then added to achieve a range of 0 to 54. Respondents scoring 27 or higher are deemed satisfied with their current job. Scores below 27 are deemed dissatisfied.

Reliability of the JIG has consistently been reported as ranging from .82 to .94 (Fields, 2002). Validity of the JIG has also constantly found global job satisfaction to be positively correlated with other global organizational variables. Most relevant to the present study, Konovsky and Cropanzano (1991) found a significant correlation between global job satisfaction and both distributive and procedural justice perceptions, using the JIG scale.

\subsection{Data Analysis}

The data were analyzed using SPSS version 18 software. Descriptive statistics were calculated to determine the levels of organizational justice, job satisfaction, and the basic characteristics of the participants. Regression analysis was conducted to determine the effects of the three independent variables of organizational justice on teachers' job satisfaction. In addition, the internal consistency of the instruments used in this study was determined by calculating Cronbach alpha coefficients.

\section{Results}

As a first step in analyzing data, scale reliability coefficients (Cronbach alpha) for the surveys used in the current study were calculated. Reliability coefficient for job satisfaction was $(0.89)$, for interactional justice $(0.83)$, for procedural justice (0.86), and for distributive justice (0.89).

\subsection{Perceptions of Organizational Justice}

The findings displayed in Table 1 show that the mean of the "total" organizational justice perceptions of the physical education teachers was 3.38. Interactional justice was the most perceived organizational justice component, followed by procedural justice and distributive justice components respectively.

Table 1. Descriptive statistics (means and standards deviation) of organizational justice dimensions ( $\mathrm{N}=166)$

\begin{tabular}{lll}
\hline OJ Subscales & Mean & Std. Deviation \\
\hline Interactional justice & 3.72 & .59 \\
Procedural justice & 3.33 & .47 \\
Distributive justice & 3.10 & .43 \\
Total & 3.38 & .29 \\
\hline
\end{tabular}

According to the percentile criteria, percentile scores of 2.6 or lower indicate low organizational justice, percentile scores between 2.61 and 3.8 display moderate organizational justice, and percentile scores of 3.8 or 
higher represent high organizational justice. Based on this definition, the teachers' perceptions of organizational justice were moderate.

\subsection{Level of Teachers' Job Satisfaction}

Results presented in Table 2 indicated that physical education teachers were generally satisfied with their work $(\mathrm{M}=32.60)$. The majority of physical education teachers $80.1 \%$ reported high levels of satisfaction and only $19.9 \%$ reported low levels of satisfaction.

Table 2. Descriptive statistics of teachers' job satisfaction

\begin{tabular}{lllll}
\hline Job satisfaction & Frequency & Percentage & Mean & Std. Deviation \\
\hline Low & 33 & $\% 19.9$ & 24.68 & 2.23 \\
High & 133 & $\% 80.1$ & 34.01 & 4.15 \\
Total & 166 & $\% 100$ & 32.60 & 5.15 \\
\hline
\end{tabular}

\subsection{Relationship between Organizational Justice and Job Satisfaction}

The results displayed in Table 3 show positive and significant correlations between all dimensions of organizational justice and teachers' job satisfaction.

Table 3. Correlations between organizational justice components and job satisfaction

\begin{tabular}{lllll}
\hline Variable & Distributive justice & Procedural justice & Interactional justice & Satisfaction \\
\hline Interactional justice & 1 & .105 & .008 & $.305^{* *}$ \\
Procedural justice & 1 & $.157^{*}$ & $.203^{* *}$ \\
Distributive justice & & 1 & $.158^{*}$ \\
Satisfaction & & & 1 \\
\hline
\end{tabular}

** Correlation is significant at the 0.01 level (2-tailed).

* Correlation is significant at the 0.05 level (2-tailed).

In order to further explain these correlational findings, a hierarchal regression analysis was used to examine if the three components of organizational justice (distributive, procedural, and interactional justice) significantly predict overall satisfaction of physical education teachers. The results of the regression presented in Table 4 indicated that interactional justice significantly predicted teachers satisfaction $(\beta=.336, p<.001)$, as did procedural justice $(\beta=.263, p<.01)$, and distributive justice $(\beta=.213, p<.01)$. The three predictor model was statistically significant, $F(3,162)=12.671, p<.000$ and explained $19 \%$ of the variance in teachers' satisfaction.

Table 4. Regression analysis with organizational justice components as predictors and teacher job satisfaction as criterion

\begin{tabular}{llllllllll}
\hline Model & beta & $\mathrm{t}$ & $\mathrm{R}$ & $\mathrm{R}^{2}$ & $\begin{array}{l}\text { Adjusted } \\
\mathrm{R}^{2}\end{array}$ & $\begin{array}{l}\mathrm{R}^{2} \\
\text { Change }\end{array}$ & F Change & $\begin{array}{l}\text { Overall } \\
\mathrm{F}\end{array}$ & Sig. \\
\hline 1 & .336 & $4.72^{* * *}$ & $.307^{\mathrm{a}}$ & .094 & .089 & .094 & $17.054^{* *}$ & & \\
2 & .263 & $3.65^{* * *}$ & $.382^{\mathrm{b}}$ & .146 & .135 & .052 & $9.853^{* *}$ & 12.671 & $.000^{\mathrm{c}}$ \\
3 & .213 & $2.97^{* *}$ & $.436^{\mathrm{c}}$ & .190 & .175 & .044 & $8.845^{* *}$ & &
\end{tabular}

a. Predictors: (Constant), interactional justice

b. Predictors: (Constant), interactional justice, procedural justice

c. Predictors: (Constant), interactional justice, procedural justice, distributive justice

$$
\begin{aligned}
& * * * p<.001 \\
& * * p<.01 \\
& * p<.05
\end{aligned}
$$




\section{Discussion}

The results obtained from this study showed that the majority of physical education teachers were satisfied in general. It might be that good payment and rewards, opportunity for promotion, and good relationships with school administration and colleagues led to this feeling of satisfaction. Another possible explanation is that all teachers are government employees. They feel secure and do not have any threat of being terminated. Job security is a factor that affects the satisfaction of employees in organizations (Saba, 2011). This finding is in line with the findings from earlier research, which suggest that school teachers tend to be generally satisfied (e.g., Abushaira, 2012; Dundar \& Tabancali, 2012; Saba, 2011; Zainalipour et al., 2010).

Perceptions of physical education teachers about organizational justice were moderately positive. This finding is in accordance with the findings from Tan (2006) and Dundar and Tabancali, (2012) studies. Their findings revealed that school teachers had a moderate perception about organizational justice.

The relationship between organizational justice and the overall job satisfaction of physical education teachers in this study appears to be significant. The results showed that the three components of organizational justice were positively correlated with teachers' job satisfaction. This finding is similar to the findings from prior research on organizational justice and job satisfaction (e.g., Bakhshi et al., 2009; Bhupatkar, 2003; Dundar \& Tabancali, 2012; Elamin \& Alomaim, 2011; Fernandes \& Awamleh, 2006; Fatt et al., 2010; Nojani et al., 2012; Schmiesing et al., 2003).

The results of the regression analysis revealed that interactional justice was the best predictor of teachers' job satisfaction followed by procedural justice and distributive justice respectively. Interactional justice concerns the quality of treatment employees receive from their leaders (Bies \& Moag, 1986). It has several aspects such as politeness, honesty, friendliness, interest, and respect (Clemmer, 1988). It seems that these aspects and the prevalence of fairness in the school culture to be the most important factors that led to securing a satisfied teacher. Previous research has contended whether interactional justice is a unique component (Cropanzano \& Greenberg, 1997; McFarlin \& Sweeney, 1997) or a sub-component to procedural justice (Bies \& Moag, 1986). The findings of the current study support the notion that interactional justice is a unique organizational justice component.

Procedural justice was also found to be a significant predictor of teachers' job satisfaction. Findings of this study showed that procedural justice accounted for $5.2 \%$ of the variance in satisfaction of physical education teachers. This finding is in line with the findings of Zainalipour et al. (2010) and Nojani et al. (2012). Their findings showed significant correlations between procedural justice and all dimensions of job satisfaction. The findings of this study are however, different from those reported by Bakhshi et al. (2009), and Fernandes and Awamleh (2006). They did not find any significant relationship between procedural justice and job satisfaction.

In addition to interactional and procedural justice, the results also identified distributive justice as a significant predictor of teachers' satisfaction. Distributive justice is pertained to perceptions of fair allocation of outcomes such as pay and promotions offered by the organization (Colquitt et al., 2001). Earlier studies showed that distributive justice was positively correlated with job satisfaction (e.g., Bakhshi et al., 2009; Fernandes \& Awameleh, 2006; Malik \& Naeem, 2011; Zainalipour et al., 2010). The results of the current study are in accordance with the results of past research suggesting that fair distribution of resources and outcomes may possibly increase the level of teachers' satisfaction.

\section{Implications}

The current study has several important implications. First, the results suggest that there is a strong relationship between the three components of organizational justice and the overall satisfaction of physical education teachers. These results suggest that school administrators should pay special attention to the importance of organizational justice at the workplace, and they must put it into practice in order to improve teachers' satisfaction and commitment. School administrators should be fair in the application of rules at schools and in distribution of work, tasks, rewards and promotions (Fatt et al., 2010). Second, the results of this study provide supporting evidence for the uniqueness of interactional justice component. Thus, school administrators should be paying more attention to several aspects such as politeness, honesty, friendliness, and respect as it will lead to high levels of teacher satisfaction. Finally, the findings may have important implications for cross-cultural research, as future avenues for research are suggested. It would be interesting, for instance, to investigate whether the relationships among organizational justice, satisfaction and other organizational variables remain the same in schools from other countries with different views about justice. 


\section{Conclusion and Suggestions for Future Research}

In conclusion, the results of the current study were consistent with previous research and added support to the literature on organizational justice and job satisfaction. Teachers' perceptions of organizational justice are important and definitely have significant effects on their satisfaction.

Future researchers can improve the general application of the present study by replicating these results using other samples and other methods (Fatt et al., 2010). The present study involved only physical education teachers from public schools in Jordan. Therefore, a recommendation is that further research should involve private schools and higher education institutions. Future research should also focus on interactional justice as a unique component of organizational justice. The existing literature on interactional justice is limited compared to the literature on distributive and procedural justice. A reason for this may be the debate over interactional justice as a unique component of organizational justice. The present findings offer support for the use of interactional justice as a unique component. Finally, more studies should be conducted in non-Western contexts such as educational context in Jordan and Arab countries since justice perceptions may vary across different cultures (Leung \& Stephan, 2001).

\section{References}

Abushaira, M. (2012). Job satisfaction among special education teachers in Jordan. International Interdisciplinary Journal of Education, 1(3), 48-56.

Adams, J. S. (1965). Inequity in social exchange. Advances in Experimental Social Psychology, 2, 267-299. http://dx.doi.org/10.1016/S0065-2601(08)60108-2

Al-Zu'bi, A. H. (2010). A study of relationship between organizational justice and job satisfaction. International Journal of Business and Management, 5(12), 102-109.

Bakhshi, A., Kumar, K., \& Rani, E. (2009). Organizational justice perceptions as predictor of job satisfaction and organization commitment. Journal of Business and Management, 4(9), 145-154.

Bhupatkar, A. A. (2003). Employees' perceptions of organizational justice on job satisfaction and organizational citizenship behavior. Unpublished Master thesis, Emporia State University, Kansas.

Bies, R. J., \& Moag, J. S. (1986). Interactional justice: Communication criteria of fairness. In R. J. Lewicki, B. H. Sheppard, \& M. H. Bazerman (Eds.), Research on negotiation in organizations (Vol. 1, pp. 43-55). Greenwich, CT: JAI Press.

Chelladurai, P. (1999). Human resource management in sport and recreation. Champaign, IL: Human Kinetics.

Clemmer, E. C. (1988). The role of fairness in customer satisfaction with services. Unpublished doctoral dissertation, The University of Maryland.

Colquitt, J. A., Conlon, D. E., Wesson, M. J., Porter, C. O., \& Ng, K. Y. (2001). Justice at the millennium: A meta-analytic review of 25 years of organizational justice research. Journal of Applied Psychology, 86(3), 425-445. http://dx.doi.org/10.1037/0021-9010.86.3.425

Cropanzano, R. (2001). Advances in organizational justice. Stanford, CA: Stanford University Press.

Cropanzano, R., \& Greenberg, J. (1997). Progress in organizational justice: Tunneling through the maze. In C. Cooper, \& I. Robertson (Eds.), Interactional review of industrial and organizational psychology (pp. 317-372). New York: Wiley.

Cropanzano, R., Byrne, Z., Bobocel, D. R., \& Rupp, D. (2001). Moral virtues, fairness heuristics, social entities, and other denizens of organizational justice. Journal of Vocational Behavior, 58(2), 164-209. http://dx.doi.org/10.1006/jvbe.2001.1791

Dawis, R. V., \& Lofquist, L. H. (1984). A psychological theory of work adjustment. Minneapolis, MN: University of Minnesota Press.

Dundar, T., \& Tabancali, E. (2012). The relationship between organizational justice perceptions and job satisfaction levels. Procedia-Social and Behavioral Sciences, 46, 5777-5781. http://dx.doi.org/10.1016/j.sbspro.2012.06.513

Elamin, A. M., \& Alomaim, N. (2011). Does organizational justice influence job satisfaction and self-perceived performance in Saudi Arabia work environment? International Management Review, 7(1), 38-49.

Fatt, C. K., Khin, E. W., \& Heng, T. N. (2010). The impact of organizational justice on employee's job satisfaction: The Malaysian companies perspectives. American Journal of Economics and Business 
Administration, 2(1), 56-63. http://dx.doi.org/10.3844/ajebasp.2010.56.63

Fernandes, C., \& Awamleh, R. (2006). Impact of organizational justice in an expatriate work environment. Management Research News, 29(11), 701-712. http://dx.doi.org/10.1108/01409170610716016

Fields, D. L. (2002). Taking the measure of work: A guide to validated scales for organizational research and diagnosis. Thousand Oaks, CA: Sage Publications, Inc.

Greenberg, J. (1987). A taxonomy of organizational justice theories. The Academy of Management Review, 12(1), 9-22.

Greenberg, J. (1993). The social side of fairness: Interpersonal and informational classes of organizational justice. In R. Cropanzano (Ed.), Justice in the workplace: Approaching fairness in human resource management (pp. 79-103). Hillsdale, NJ: Erlbaum.

Greenberg, J. G. (1990). Organizational justice: Yesterday, today, and tomorrow. Journal of Management, 16, 399-432. http://dx.doi.org/10.1177/014920639001600208

Greenberg, J. G., \& Colquitt, J. A. (2005). Handbook of organizational justice. New Jersey: Lawrence Erlbaum Associates Publishers.

Greenberg, J., \& Baron, R. A. (2008). Behavior in organizations (9th ed.). Upper Saddle River, NJ: Prentice-Hall.

Gurbuz, S., \& Mert, I. S. (2009). Validity and reliability testing of organizational justice scale: An empirical study in a public organization. Review of Public Administration, 42(3), 117-139.

Ironson, G. H., Smith, P. C., Brannick, M. T., Gibson, W. M., \& Paul, K. B. (1989). Construction of a Job in General scale: A comparison of global, composite, and specific measures. Journal of Applied Psychology, 74, 193-200. http://dx.doi.org/10.1037/0021-9010.74.2.193

Konovsky, M. A., \& Cropanzano, R. (1991). Perceived fairness of employee drug testing as a predictor of employee attitudes and job performance. Journal of Applied Psychology, 76(5), 698-707. http://dx.doi.org/10.1037/0021-9010.76.5.698

Leung, K., \& Stephan, W. G. (2001). Social justice from a cultural perspective. In D. Matsumoto (Ed.), The handbook of culture and psychology (pp. 375-410). New York: Oxford University Press.

Malik, M. E., \& Naeem, B. (2011). Role of perceived organizational justice in job satisfaction: Evidence from higher education institutions of Pakistan. Interdisciplinary Journal of Contemporary Research in Business, $3(8), 662-673$.

Masterson, S. S., Lewis, K., Goldman, B. M., \& Taylor, M. S. (2000). Integrating justice and social exchange: The differing effects of fair procedures and treatment on work relationships. Academy of Management Journal, 43(4), 738-748. http://dx.doi.org/10.2307/1556364

Moorhead, G., \& Griffin, R. (2004). Organizational behavior: Managing people and organizations (7th ed.). Boston, Houghton Mifflin Company.

Niehoff, B. P., \& Moorman, R. H. (1993). Justice as a mediator of the relationship between methods of monitoring and organizational citizenship behavior. Academy of Management Journal, 36(3), 527-556. http://dx.doi.org/10.2307/256591

Nojani, M. I., Arjmandnia, A. A., Afrooz, G. A., \& Rajabi, M. (2012). The study on relationship between organizational justice and job satisfaction in teachers working in general, special and gifted education systems. Procedia-Social and Behavioral Sciences, 46, 2900-2905. http://dx.doi.org/10.1016/j.sbspro.2012.05.586

Saba, I. (2011). Measuring the job satisfaction level of the academic staff in Bahawalpur colleges. International Journal of Academic Research in Business and Social Sciences, 1(1), 12-19.

Schappe, S. P. (1998). Understanding employee job satisfaction: The importance of procedural and distributive justice. Journal of Business and Psychology, 12(4), 493-503. http://dx.doi.org/10.1023/A:1025007307058

Schmiesing, R. J., Safrit, R. D., \& Gliem, J. A. (2003). Factors affecting OSU extension agents' perceptions of organizational justice and job satisfaction. Journal of International Agricultural and Extension Education, 10(2), 25-35. http://dx.doi.org/10.5191/jiaee.2003.10203

Spector, P. E. (1997). Job satisfaction: Application, assessment, causes, and consequences. Thousand Oaks, CA: Sage Publications Inc. 
Tan, C. (2006). The primary school teachers' perceptions about organizational justice. Unpublished Master thesis, Firat University, Turkey.

Thibaut, J., \& Walker, L. (1975). Procedural justice: A psychological analysis. Hillsdale, NJ: Erlbaum.

Thorn, D. (2010). Perceptions of organizational justice, job satisfaction, and organizational commitment in intercollegiate athletics: A study of NCAA men's sport coaches. Unpublished doctoral dissertation, University of Louisville, Kentucky.

Zainalipour, H., Fini, A. A., \& Mirkamali, S. M. (2010). A study of relationship between organizational justice and job satisfaction among teachers in Bandar Abbas middle school. Procedia-Social and Behavioral Sciences, $\quad 5, \quad 1986-1990 . \quad$ Retrieved from $\mathrm{http} / / / \mathrm{www} . \mathrm{sciencedirect.com}$ http://dx.doi.org/10.1016/j.sbspro.2010.07.401

\section{Copyrights}

Copyright for this article is retained by the author(s), with first publication rights granted to the journal.

This is an open-access article distributed under the terms and conditions of the Creative Commons Attribution license (http://creativecommons.org/licenses/by/3.0/). 